\title{
Interaction between C2ORF68 and HuR in human colorectal cancer
}

\author{
ZHAOXU LV, KUNYAN HE, LIHONG SHI, KAI SHI, TINGTING JIANG and YAO CHEN \\ Department of Human Anatomy, West China School of Basic Medical Sciences and Forensic Medicine, \\ Sichuan University, Chengdu, Sichuan 610041, P.R. China
}

Received April 26, 2018; Accepted October 31, 2018

DOI: $10.3892 /$ or.2019.6973

\begin{abstract}
The detailed molecular mechanisms underlying the carcinogenesis of colorectal carcinoma (CRC) remain unknown. Therefore, the present study was designed to investigate the effect of the relationship between C2ORF68 and HuR in regards to the carcinogenesis of CRC. Immunohistochemistry, immunofluorescence, flow cytometry, Transwell migration and CCK-8 assays, co-immunoprecipitation, qRT-PCR and western blot analysis were performed. The results revealed that expression of C2ORF68 was significantly upregulated in the cytoplasm and nucleus in rectal cancer, and upregulation of the expression of C2ORF68 was associated with lymph node metastasis and pathological grade. C2ORF68 and HuR were found to be mainly localized in the nucleus in both SW480 and LoVo cells. In $\mathrm{LoVO}^{+c 2 o r f 68,-H u R}$ and $\mathrm{LoVO}^{+c 2 o r f 68}$ cells, the cell apoptosis rate was significantly decreased, cell proliferation rate was significantly increased, and the cell migration rate was only significantly increased in the $\mathrm{LoVO}^{+c 2 o r f 68}$ cells. In SW480 ${ }^{-c 20 r f 68,-H u R}$, SW480-c2orf68 and SW480-HuR , the cell apoptosis rate was significantly increased. At the same time, cell proliferation and the cell migration rate were significantly decreased. The mRNA and protein expression levels of C2orf68, HuR, Bcl-2, c-Myc, cyclin D and $c y c l i n A$ were upregulated, while the expression of Bax was downregulated in $\mathrm{LoVo}^{+c 2 o r f 68}$ and $\mathrm{LoVo}^{+c 20 r f 68,-H u R}$ cells. Expression levels of C2orf68, $\mathrm{HuR}, \mathrm{Bcl}-2, \mathrm{c}$-Myc, cyclin D and cyclin $A$ were downregulated while Bax was upregulated in the SW480-c2orf68,-HuR , SW480 ${ }^{-c 2 o r f 68}$ and SW480-HuR cells. In conclusion, it is suggested that $c 20 r f 68$ is a potential carcinogenesis factor in rectal cancer. Furthermore, 2 orf68 may have a synergistic effect with $H u R$ in the onset and development of CRC.
\end{abstract}

Correspondence to: Professor Yao Chen, Department of Human Anatomy, West China School of Basic Medical Sciences and Forensic Medicine, Sichuan University, 17 People's South Road, Chengdu, Sichuan 610041, P.R. China

E-mail: chenyao62@scu.edu.cn

Key words: C2ORF68, HuR, colorectal cancer, interaction

\section{Introduction}

Colorectal cancer (CRC) is the third most commonly diagnosed malignant tumor and is the fourth leading cause of cancer-related death worldwide (1). It is largely diagnosed in individuals $>50$ years of age (2). CRC patients in the early stage [tumor-node-metastasis (TNM) stage I and II] present with a prolonged 5-year survival following surgical excision; the 5-year survival is up to $95 \%$ and $60-80 \%$ for stage I and II, respectively. However, existing therapies for CRC usually exhibit a limited effect on patient prognosis, and the 5-year survival of patients in stages III and IV can be as low as 35 and $10 \%$ (3). Research has shown that CRC incidence and mortality can be decreased significantly through screening programs, while CRC screening is only offered to very few individuals worldwide based on the CRC incidence rate, national economic level and medical security system (4). A previous study demonstrated that germline mutations enable next generation hereditary susceptibility to CRC accounting for 6-7\%. In addition, mutations in DNA repair genes and signal transduction genes also contribute to the occurrence of CRC. In addition to inherited genetic mutations, environmental factors, such as the heavy consumption of alcohol, smoking habit, increased body fat and diets high in fat, salt and red and processed meat, also play important roles (5). However, more and more studies have shown that CRC displays accumulated defects in the activation of oncogenes and the inactivation of tumor-suppressor genes (TSGs) (6). Except for classical CRC risk factors, such as: KRAS, TP53, $A P C$ and markers for microsatellite instability (MSI) $(7,8)$, an impressive body of literature indicates that multiple factors such as hsa-miR-19a (9), PROK2 (10), B7-H3 (11), DSCC1 (12) and microRNAs (13) are involved in the occurrence of CRC. A recent study revealed that the dysbiosis of microbial communities in the human body are also associated with gastrointestinal tract cancer, such as gastric and colorectal cancer. Moreover, a hypothesis called 'Alpha bug' considers that some bacteria could alter the primary bacterial community and the remodeled bacterial community could promote CRC by strengthening the mucosal immune response (14). Although numerous studies have shown that the pathogenesis of CRC is multifactorial, the detailed mechanisms remain unclear at present.

C2ORF68, which belongs to the UPF0561 family, contains 166 amino acids, and the monoisotopic molecular weight is 
18.6033 kDa (15). The predicted potential NLS and NES sequences of C2ORF68 and the domain of the EF hand indicate that $c 2$ orf 68 could function as a cell cycle regulator in the nucleus, which may explain its possible role in CRC pathogenesis. Our early research suggests that C2ORF68 may regulate colon cancer cell apoptosis, proliferation, migration and cell cycle distribution through the PI3K/Akt/mTOR pathway (16). We also suggested that C2ORF68 may promote the carcinogenesis of CRC and play a vital role in the pathogenesis of CRC through activation of the Wnt/ $\beta$-catenin signaling pathway (17), such as the upregulation of $\beta$-catenin, survivin, cyclin DI and $c-M y c$, and the downregulation of $G S K-3 \beta$ in CRC cells. Although it was demonstrated that C2ORF68 may play a role in the occurrence of CRC and may be a potential oncogene in $\mathrm{CRC}$, its specific molecular mechanism remains dim.

Our previous study indicated that C2ORF68 may play an important role in the occurrence and development of CRC through the PI3K/AKT/mTOR and Wnt/ $\beta$-catenin signaling pathways. However, its exact mechanisms are still mysterious. To elucidate the role and status of C2ORF68 in the carcinogenesis of colorectal adenocarcinoma, we carried out bioinformatic analyses. It was found that 12 proteins interact with c2orf68, including KLHL15, GMNN, SMG6, GNE, DDHD2, PIR, ELAVL1 (HuR), NAGK, XPO1, HSPA9, JOSD2 and GUK1. $\mathrm{HuR}$ is an RNA-binding protein whose expression level is widely upregulated in many types of human cancer, including CRC. A previous study showed that the HuR expression level is closely related to AKT phosphorylation and increased cytoplasmic abundance of HuR in human cancer may be associated with oncogenic activation of AKT signaling (18). To determine the interaction between C2ORF68 and HuR, and their roles in the occurrence of CRC, immunohistochemistry (IHC), immunofluorescence (IF), flow cytometry, Transwell migration and CCK-8 assays, co-immunoprecipitation (co-IP), qRT-PCR and western blot analysis were performed. The results revealed that C2ORF68 has a synergistic effect with HuR, and their role in the onset and the development of CRC may be through the upregulated expression of Bcl-2, - -Myc, cyclin A and cyclin DI and the downregulation of $B a x$, coonsequently promoting cell proliferation and inhibiting cell apoptosis.

\section{Materials and methods}

Bioinformatic analysis. BioGRID is an interaction database with data based on comprehensive curation efforts. The interactive proteins for C2ORF68 were predicted through the BioGrid repository (https://thebiogrid.org/).

Tissue microarray. A tissue microarray including 90 rectal cancer tissues and adjacent normal tissues were purchased from Shanghai Xinchao (Shanghai Xinchao Biological Co. Ltd., Shanghai, China). The Medical Research Ethics Committee of Sichuan University approved the sample acquisition (Chengdu, China), and a written informed consent was also obtained from all patients.

Immunohistochemistry (IHC) of the rectal cancer tissue microarray. IHC was performed as previously described (19). Clinicopathological parameters of the CRC patients are shown in Table I. The primary antibody $(\mathrm{Ab})$ used for IHC was mouse monoclonal C2ORF68 Ab (1:200; BIO014915; Beacombio, Birmingham, UK). The expression level of C2ORF68 protein in rectal cancer tissues were scored by three independent examiners. The level of C2ORF68 staining pattern was scored according to four subgroups: i) Negative (-); ii) weak (+); iii) moderate (++); and iv) strong (+++).

Cell lines and cell culture. Human colon cancer cell lines, SW480 and LoVo [American Type Culture Collection (ATCC) Manassas, VA, USA], were cultured in Dulbecco's modified Eagle's medium (DMEM; HyClone; GE Healthcare Life Sciences, Logan, UT, USA) which contained $10 \%$ fetal bovine serum (FBS), penicillin (100 IU/ml) and streptomycin (100 IU/ml). The cells were grown at $37^{\circ} \mathrm{C}$ in a humidified atmosphere with $5 \% \mathrm{CO}_{2}$. The cells were harvested when they were in the exponential growth phase and then the experiments stated above were performed.

Immunofluorescence (IF). For immunostaining, the SW480 and LoVo cells were fixed with $4 \%$ paraformaldehyde for $20 \mathrm{~min}$, permeabilized with $0.5 \%$ Triton X-100 for $15 \mathrm{~min}$ and blocked with $3 \%$ bovine serum albumin (BSA) for $30 \mathrm{~min}$ at room temperature. The treated cells were then incubated with mouse monoclonal anti-C2ORF68 (1:100) and rabbit polyclonal anti-HuR (dilution 1:100; cat. no. ab200342; Abcam, Cambridge, UK) overnight at $4^{\circ} \mathrm{C}$, and finally incubated with FITC-labeled and TRITC-labeled secondary Ab for $30 \mathrm{~min}$ under the conditions of protection from light at room temperature. Each step was followed by two 5-min washes in PBS. The nuclei were counterstained using DAPI, and observed using an Olympus BX53 fluorescence microscope (Olympus, Hamburg, Germany).

siRNA selection and transient transfection. siRNAs for c2orf68 (siRNA sequences, 5'-CUAUGAAGAGUCCGG UGA AdTdT-3' and 3'-dTdTCUUCUCCAUAACUUACG AU-5') and $H u R$ (siRNA sequences, 5'-GGUUGCGUUUAU CCGGUUUdTdT-3' and 3'-dTdTCCAACGCAAAUAGG CCAAA-5') were designed and synthesized by RiboBio (Guangzhou, China). Using the blank and negative control groups, the transfection was performed with $100 \mathrm{nM}$ of siRNA and Invitrogen ${ }^{\mathrm{TM}}$ Lipofectamine $2000^{\mathrm{TM}}$ (Thermo Fisher Scientific, Inc., Waltham, MA, USA) to induce the knockdown of $c 2 \mathrm{orf} 68 / \mathrm{HuR}$ expression. After transfection for $6 \mathrm{~h}$, the cells were respectively incubated in fresh DMEM for $48 \mathrm{~h}$ to detect the mRNA expression level and for $72 \mathrm{~h}$ to detect the protein expression level.

Strain, plasmid, plasmid extraction and overexpression. The 2 orf68 gene was synthesized and inserted into the XhoI/EcoRI site of the pcDNA3.1 eukaryotic expression vector (Pharma Co., Shanghai, China), which was verified by restriction digestion followed by sequencing (Beijing Genomic Institute, Beijing, China) in our previous study (17). The microbial strain and plasmids used in the present study were Escherichia coli (E. coli), DH5 $\alpha$ and the pcDNA3.1-c2orf68 eukaryotic expression vector. The plasmid extraction process was carried out by TIANprep Plasmid Mini kit introduction (cat. no. DP103-02; Tiangen Biotech Co., Ltd., Beijing, China). 
Table I. Association of the expression of C2ORF68 with the clinicopathological parameters of the CRC samples.

\begin{tabular}{|c|c|c|c|c|c|c|}
\hline \multirow[b]{2}{*}{ Parameter } & \multicolumn{4}{|c|}{ Expression intensity (n) } & \multirow[b]{2}{*}{$\chi^{2}$} & \multirow[b]{2}{*}{ P-value } \\
\hline & +++ & ++ & ++ & - & & \\
\hline \multicolumn{7}{|l|}{ Sex } \\
\hline Female & 16 & 25 & 11 & 2 & & \\
\hline Male & 14 & 16 & 4 & 2 & 1.568 & 0.698 \\
\hline \multicolumn{7}{|l|}{ Age, years } \\
\hline$\leq 60$ & 13 & 11 & 8 & 2 & & \\
\hline$>60$ & 17 & 30 & 7 & 2 & 4.283 & 0.233 \\
\hline \multicolumn{7}{|l|}{ TNM stage } \\
\hline I & 4 & 13 & 2 & 1 & & \\
\hline II & 13 & 19 & 3 & 1 & & \\
\hline III & 12 & 9 & 10 & 2 & & \\
\hline IV & 1 & 0 & 0 & 0 & 13.882 & 0.115 \\
\hline \multicolumn{7}{|c|}{ Differentiation degree } \\
\hline Well & 1 & 7 & 2 & 1 & & \\
\hline Moderate & 19 & 32 & 10 & 3 & & \\
\hline Low & 10 & 2 & 3 & 0 & 13.047 & 0.043 \\
\hline \multicolumn{7}{|c|}{ Lymph node metastasis } \\
\hline Yes & 13 & 9 & 10 & 2 & & \\
\hline No & 17 & 32 & 5 & 2 & 10.343 & 0.013 \\
\hline \multicolumn{7}{|c|}{ Survival status } \\
\hline Surviving & 15 & 25 & 10 & 3 & & \\
\hline Deceased & 15 & 16 & 5 & 1 & 1.310 & 0.727 \\
\hline
\end{tabular}

CRC, colorectal cancer; TNM, tumor-node-metastasis.

The LoVo cells at a density of $3 \times 10^{5}$ cells/well in a 6 -well plate transfected with $5 \mu$ interference fragment or negative control (NC) vector using Lipofectamine 2000 which was then replaced with fresh growth medium after 6 h. Following culture for $48 \mathrm{~h}$, the transfected LoVo cells were treated with $600 \mathrm{lg} / \mathrm{ml}$ of G418 (Sigma-Aldrich; Merck KGaA, Darmstadt, Germany). After 14 days, the monoclonal cells were cultured in the presence of $300 \mathrm{lg} / \mathrm{ml}$ of G418.

Co-immunoprecipitation(co-IP).Forco-IP,pcDNA3.1-c2orf68 eukaryotic expression vector was transfected for $60 \mathrm{~h}$ in SW620 cells. Then the cells with overexpression of $c 20 r f 68$ were lysed with mild lysis buffer containing several protease inhibitors for $30 \mathrm{~min}$, and the cell lysates were separated by centrifugation at $15,000 \times \mathrm{g}$ for $20 \mathrm{~min}$. Next, a modicum of cell lysates was reserved and utilized for western blot analysis. Next, the mouse anti-C2ORF68 Ab and rabbit anti-HuR Ab were added into the cell lysates for one night at $4^{\circ} \mathrm{C}$. On the following day, $100 \mu \mathrm{l}$ protein $\mathrm{A}+\mathrm{G}$ were added into the compound and incubated for $4 \mathrm{~h}$. Subsequently, the sediments were gathered and the beads were washed twice using mild lysis buffer. After that, the same volume of 2X SDS-PAGE loading buffer was used to elute the protein which was absorbed on sepharose beads. Finally, the protein was used for SDS-PAGE.
Cell proliferation assay. The cell proliferation assay was performed as previously described (19). Plates were read at an absorbance wavelength of $450 \mathrm{~nm}$ with the help of a microplate reader (Model 680; Bio-Rad Laboratories, Hercules, CA, USA). Each transfection group had six replicates, and the experiment was repeated three times.

Flow cytometry. Flow cytometry was performed as previously described (19). Then, the results were analyzed by flow cytometry (FACSAria II Cell Sorter; BD Biosciences, Franklin Lakes, NJ, USA). Each transfection group had three replicates, and the experiment was repeated three times.

Cell migration assay. Cell migration assay was performed as previously described (19). Migrated cells were quantified by counting the stained cells under a microscope (Model 680; Bio-Rad Laboratories) at x200 magnification. For each well, five random fields were selected to determine the total number of migrated cells. The assay was performed in triplicate and repeated three times.

$q R T-P C R$ analysis. qRT-PCR analysis was performed as previously described (19). The sequences of forward and reverse primers are shown in Table II. The amplification was performed on a Bio-Rad C1000 Touch Thermal Cycler 
Table II. Primer sequences for reverse transcription-quantitative polymerase chain reaction.

\begin{tabular}{|c|c|c|c|}
\hline Gene & Primer sequence $\left(5^{\prime} \rightarrow 3^{\prime}\right)$ & Location & Product length, bp \\
\hline \multirow[t]{2}{*}{ c2orf68 } & F: GAAGAGTCCGGTGAAAGCAG & $315-336$ & \multirow[t]{2}{*}{169} \\
\hline & R: TACGCAACTTGAGGGCTTCT & $483-462$ & \\
\hline \multirow[t]{2}{*}{$H u R$} & F: ACCCAGGATGAGTTACGA & $245-264$ & \multirow[t]{2}{*}{125} \\
\hline & R: GCCCAAACCGAGAGAACAT & $369-349$ & \\
\hline \multirow[t]{2}{*}{ Bax } & F: AAGCTGAGCGAGTGTCTCAAG & $172-192$ & \multirow[t]{2}{*}{178} \\
\hline & R: CAAAGTAGAAAAGGGCGACAAC & $349-328$ & \\
\hline \multirow[t]{2}{*}{$B c l 2$} & F: GTTTGATTTCTCCTGGCTGTCTC & $1-23$ & \multirow[t]{2}{*}{133} \\
\hline & R: GAACCTTTTGCATATTTGTTTGG & $649-627$ & \\
\hline \multirow[t]{2}{*}{$c-M y c$} & F: TCAAGAGGCGAACACACAAC & $1,631-1,550$ & \multirow[t]{2}{*}{110} \\
\hline & R: GGCCTTTTCATTGTTTTCCA & $1,740-1,721$ & \\
\hline \multirow[t]{2}{*}{ Cyclin D1 } & F: GTGGCCTCTAAGATGAAGGAGA & $534-555$ & \multirow[t]{2}{*}{169} \\
\hline & R: GGAAGTGTTCAATGAAATCGTG & $702-681$ & \\
\hline \multirow[t]{2}{*}{ Cyclin A } & F: TGTCTCATGGACCTTCACCA & $1,541-1,560$ & \multirow[t]{2}{*}{117} \\
\hline & R: CTCTGGTGGGTTGAGGAGAG & $1,657-1,638$ & \\
\hline \multirow[t]{2}{*}{$G A P D H$} & F: GGAAGGTGAAGGTCGGAGT & $179-197$ & \multirow[t]{2}{*}{117} \\
\hline & R: TGAGGTCAATGAAGGGGTC & $295-277$ & \\
\hline
\end{tabular}

F, forward; R, reverse.

(Bio-Rad Laboratories). The GAPDH gene was used as an endogenous control, and the $\Delta \Delta \mathrm{Cq}(20)$ method was used to quantify the data, and the experiment was repeated three times.

Western blot analysis. Western blotting was performed as previously described (19). The primary antibodies used for western blotting were as follows: C2ORF68 (cat. no. ab81363; Abcam, Cambridge, UK), Bcl-2 (cat. no. sc-492; Santa Cruz Biotechnology, Inc., Dallas, TX, USA), Bax (cat. no. sc-623; Santa Cruz Biotechnology, Inc.), c-Myc (cat. no. ab32072; Abcam), (cat.no.ab200342; Abcam), cyclin D (cat.no. ab134175; Abcam), cyclin A (cat. no. ab181591; Abcam) and $\beta$-actin (cat. no. sc-8432; Santa Cruz Biotechnology, Inc.). All the primary antibodies used in this step at 1:1,000 dilution. Signals detection were performed through a Gel Imaging system (ProteinSimple, Santa Clara, CA, USA). Subsequent densitometry analysis were conducted using ImageJ (version $1.52 \mathrm{~g}$; National Institutes of Health, Bethesda, MD, USA).

Statistical analysis. Statistical analysis was performed by SPSS software (version 19.0; IBM Corp., Armonk, NY, USA). All experiments were performed three times, and all data are expressed as mean \pm SD. Student's t-test and one-way ANOVA were used for statistical analysis. Multiple comparison between the groups was performed using the S-N-K method. A P-value $<0.05$ was considered to indicate a statistically significant result.

\section{Results}

From the BioGrid database, it is found that there are 12 proteins which may interact with C2ORF68, including KLHL15, GMNN, SMG6, GNE, DDHD2, PIR, ELAVL1(HuR), NAGK, XPO1, HSPA9, JOSD2 and GUK1 (Fig. 1).

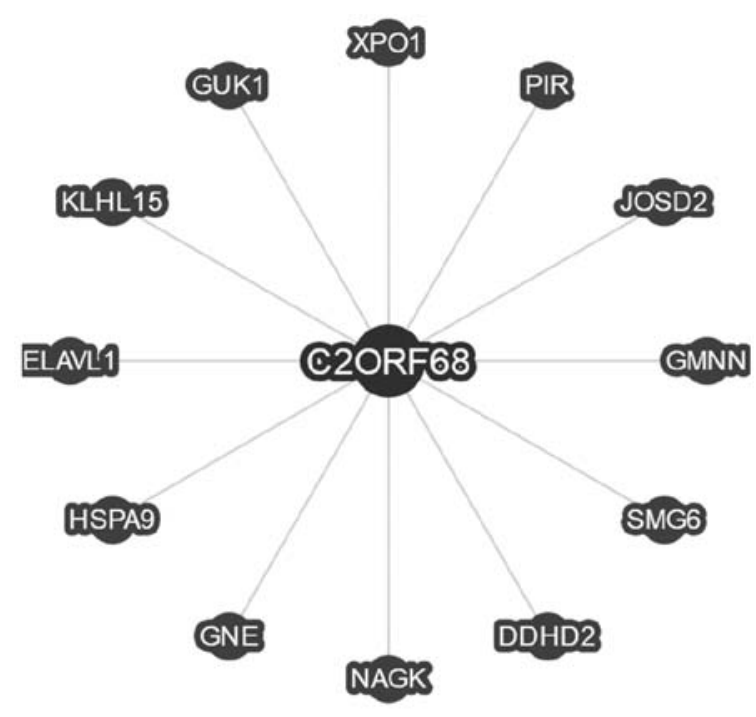

Figure 1. Interactive proteins for C2ORF68.

Expression of C2ORF68 in the rectal cancer tissue microarray. The representative cytoplasmic staining of C2ORF68 in the rectal cancer tissue microarray is shown in Fig. $2 \mathrm{~A}-\mathrm{C}$ (magnification, $\mathrm{x} 400$ ). Our previous study (15) demonstrated that C2ORF68 presents two different staining patterns, including nuclear staining and cytoplasmic staining. In line with the observation in IF, C2ORF68 is a predominantly nuclear protein, but cytoplasmic C2ORF68 localization may play a vital role in the occurrence of $\mathrm{CRC}$. In the rectal cancer tissue microarray (Fig. 2A), C2ORF68 protein expression was detected in $95.56 \%(86 / 90)$ of the cancer samples. Among these, $4.44 \%$ (4/90), $16.67 \%$ (15/90), $45.56 \%$ (41/90) and 

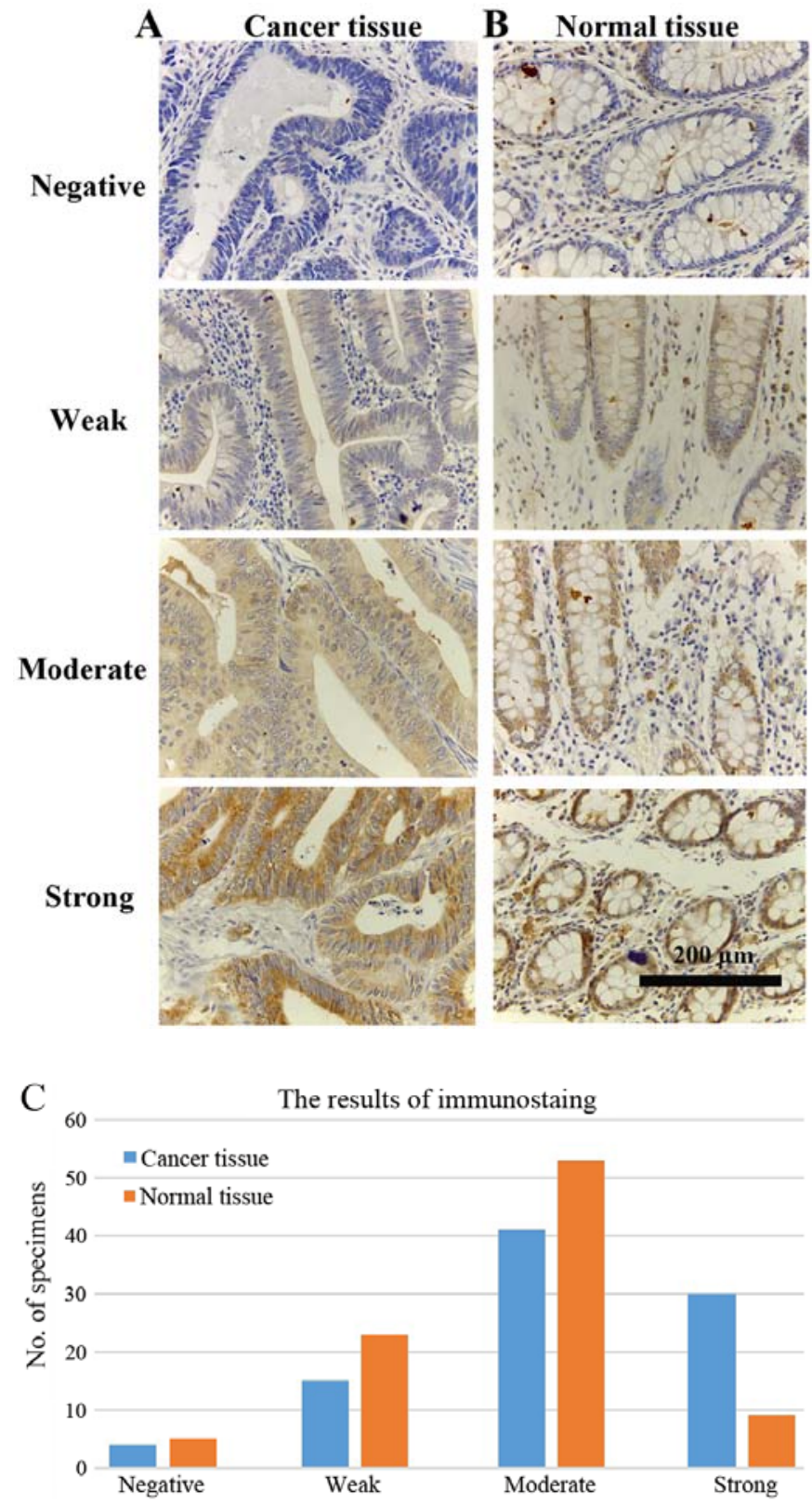

Figure 2. Representative immunohistochemical expression patterns of c2orf68 in (A) rectal cancer tissues and (B) normal rectal tissues. (C) The immunostaining result of C2ORF68 in 90 rectal cancer sand adjacent normal tissues.

$33.33 \%(30 / 90)$ of these cases exhibited negative (-), weak (+), moderate (++) and strong (+++) C2ORF68 protein staining, respectively. In contrast, $5.56 \%$ (5/90), $25.56 \%$ (23/90), $58.89 \%(53 / 90)$ and $10 \%(9 / 90)$ of normal rectal specimens exhibited negative (-), weak (+), moderate (++) and strong $(+++)$ C2ORF68 protein staining, respectively (Fig. $2 \mathrm{C}$ ). We selected five nonoverlapping views randomly from each image and calculated the mean optical density. Then, the difference in mean optical density between rectal cancer and adjacent normal tissue was analyzed by statistical analysis. It was showed that compared with the adjacent normal rectal tissues, the expression of C2ORF68 was significantly increased in the rectal cancer tissues $(\mathrm{P}<0.05)$. In addition, we also researched the relationship between the expression of C2ORF68 and clinical parameters. Significant associations were noted between
A
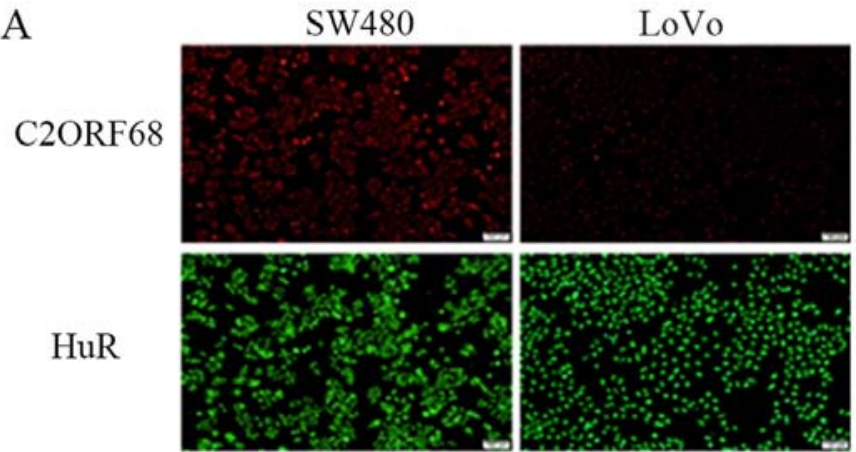

HuR
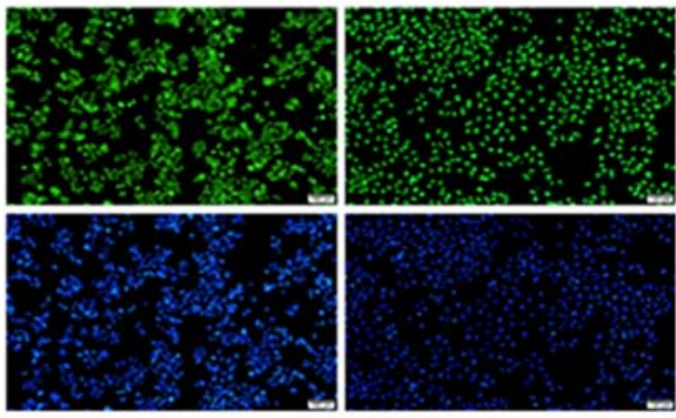

DAPI
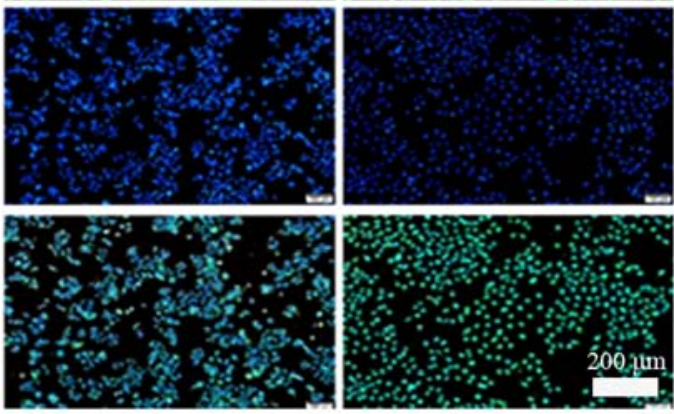

B

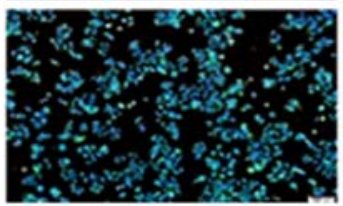

Input IgG C2ORF68
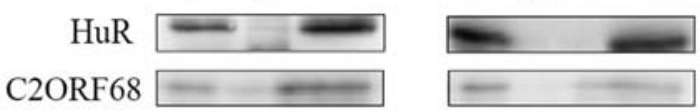

Figure 3. (A) Double immunostaining for the indicated localization of c2orf68 (red) and HuR (green) in SW480 cells and LoVo cells. (B) Co-IP for direct interaction between C2ORF68 and HuR. co-IP, co-immunoprecipitation.

C2ORF68 expression and pathological grade $(\mathrm{P}<0.05)$ and lymph node metastasis $(\mathrm{P}<0.05)$. However, the association between C2ORF68 expression and age, sex and TNM stage was not statistically significant.

Cellular localization of C2ORF68 and HuR in SW480 and LoVo cells. The results revealed that C2ORF68 and HuR were localized mainly in the nucleus in both SW480 and LoVo cells (Fig. 3A) (magnification, x100). BioGrid predicted that there is an interaction between C2ORF68 and HuR. It was shown that C2ORF68 interacts with HuR by Co-IP (Fig. 3B).

Cell apoptosis, cell proliferation and cell migration in $\mathrm{LoVO}^{+\mathrm{c} 20 r f 68,-\mathrm{HuR}}$ and $\mathrm{LoVo}^{+c 2 o r f 68}$ cells. Following transfection for $24 \mathrm{~h}$, flow cytometry was performed to analyze $c 2$ orf 68 and $H u R$-induced cell cycle arrest and apoptosis in colon cancer cells. The cell apoptosis rate of $\mathrm{LoVo}^{+c 20 r f 68,-H u R}$ and $\mathrm{LoVo}^{+c 20 r f 68}$ cells was significantly decreased compared to that of the $\mathrm{LoVo}^{-N C}$ and LoVo cells (Fig. 4B, P<0.05). There was no statistical significance noted between $\mathrm{LoVo}^{+c 20 r f 68,-H u R}$ and $\mathrm{LoVo}^{+c 2 o r f 68}$ cells, $\mathrm{LoVo}^{-N C}$ and $\mathrm{LoVo}$ cells. Compared with the control group, $\mathrm{LoVo}^{+c 20 r f 68}$ and $\mathrm{LoVo}^{+c 20 r f 68,-H u R}$ cell proliferation was significantly increased $(\mathrm{P}<0.05)$; and the cell proliferation of $\mathrm{LoVo}^{+c 2 o r f 68}$ cells was statistically significantly different when compared with that of $\mathrm{LoVo}^{+c 20 r f 68,-H u R}$ cells (Fig. 4C, $\mathrm{P}<0.05$ ). Following transfection for $24 \mathrm{~h}$, the number of migrated $\mathrm{LoVo}^{+c 2 o r f 68,-H u R}, \mathrm{LoVO}^{+c 20 r f 68}, \mathrm{LoVo}^{-N C}$ and LoVo cells was $223 \pm 24,379 \pm 33,239 \pm 31$ and $244 \pm 26$, respectively. The number of migrated $\mathrm{LoVo}^{+c 20 r f 68}$ cells was 
A $\quad \mathrm{LoVo}^{+220 r 68 \mathrm{~s}}$

$\mathrm{LoVo}^{+c 20 r f 68,-H u R}$

$\mathrm{LoVo}^{-N C}$

LoVo
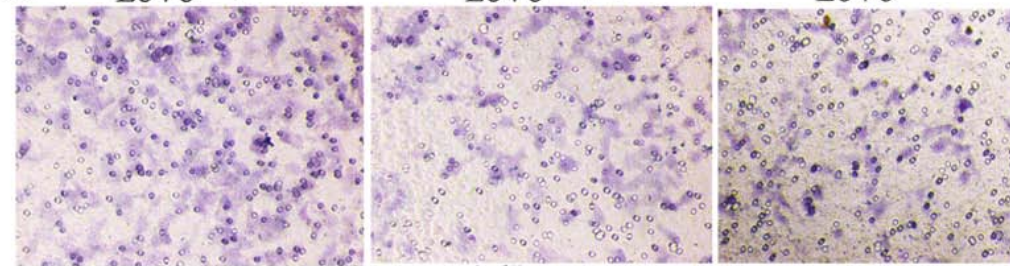

$\mathrm{LoVo}^{+c 20 r f 68}$
$\mathrm{~A} 04+81$

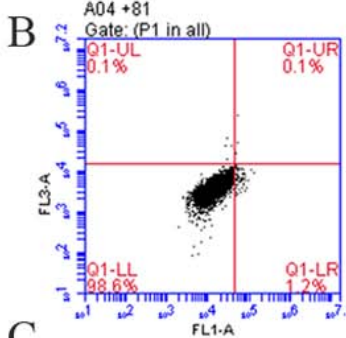

C

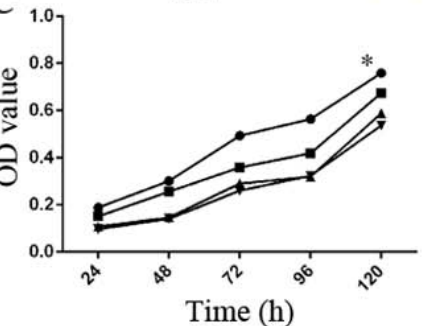

$\mathrm{LoVO}^{+\mathrm{c} 20}$
$\mathrm{~A} 06+81$-hur

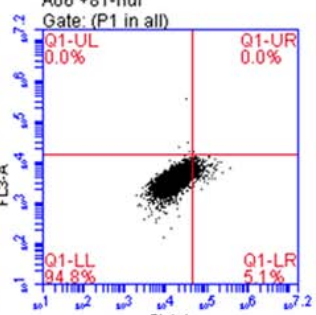

$\mathrm{LoVo}^{-N C}$
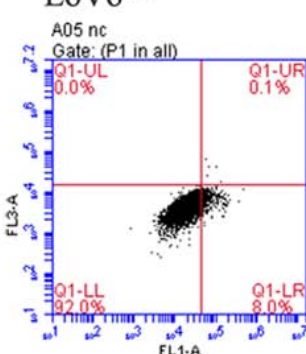

LoVo

A07 blank

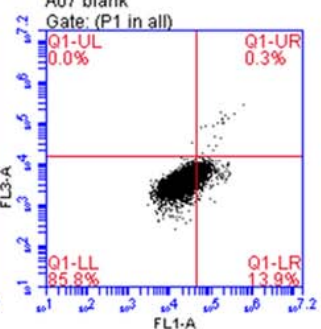

- LoVo

$\rightarrow \mathrm{LoVo}^{-\mathrm{NC}}$

- LoVo ${ }^{+c 20 r f 8 s,-H u R}$

- $\mathrm{LoVo}^{+c 20 r f 68}$

Figure 4. (A) Cell migration was observably increased in $\mathrm{LoVo}^{+c 2 o r f 68}$ cells. The number of migrated $\mathrm{LoVo}^{+c 20 r f 68}$ cells was significantly higher than that of the $\mathrm{LoVo}^{+c 20 r f 68,-H u R}$ cells, while there was no observable difference between $\mathrm{LoVo}^{+c 20 r f 68,-H u R}$ and LoVo cells. (B) In the $\mathrm{LoVo}^{+c 20 r f 68}$ and $\mathrm{LoVo}^{+c 20 r f 68,-H u R}$ cells, cell

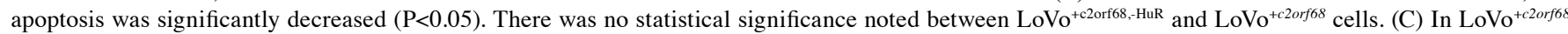
and $\mathrm{LoVo}^{+c 20 r f 68,-H u R}$ cells, cell proliferation was increased. The cell proliferation of $\mathrm{LoVo}^{+c 2 o r f 68}$ cells was statistically significant when compared with that of $\mathrm{LoVO}^{+c 2 o r f 68,-H u R}$ cells $(\mathrm{P}<0.05) .{ }^{*} \mathrm{P}<0.05$.

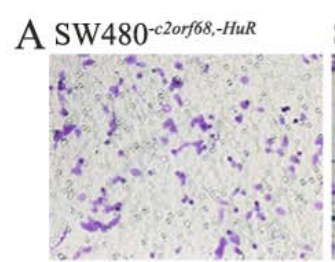
SW480 0 -c2orf68,-HuR

B

A A06-81-hur



C


SW480-HuR
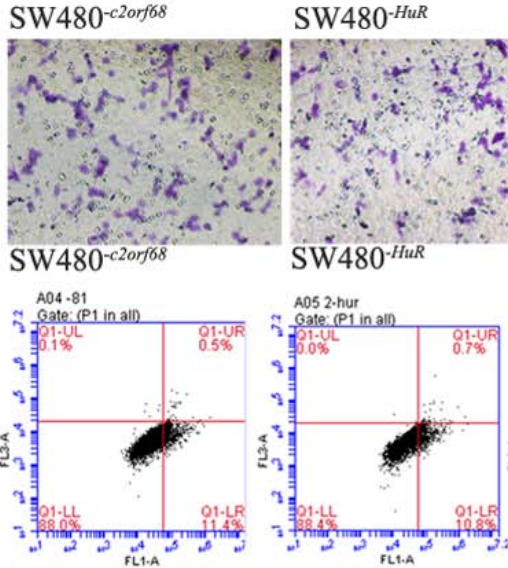

$\leftarrow$ SW480

$\rightarrow$ SW $480^{-N C}$

- SW480-HaR

$\rightarrow$ SW480-201568

$\rightarrow$ SW480-20orfo8,-HuR
SW480-NC

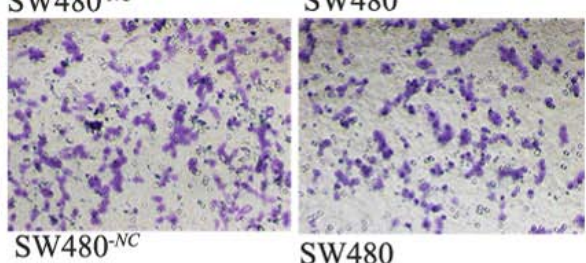

SW480-NC

SW480
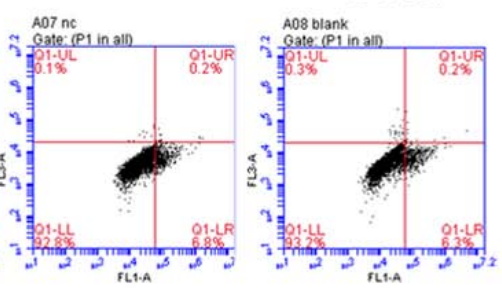

Figure 5. (A) Compared with the blank group, the number of migrated cells was observably inhibited in the SW480-c20rf68,-HuR, SW480 $0^{-c 20 r f 68}$ and SW480 $0^{-H u R}$ cells. However, the number of SW480-c2orf68,-HuR cells that migrated was observably less than that of SW480-c2orf68 and SW480-HuR cells $(\mathrm{P}<0.05)$. (B) The apoptosis rates of SW480-c20rf68,-HuR, $\mathrm{SW} 480^{- \text {-20rf68 }}$ and SW480-HuR cells were significantly increased $(\mathrm{P}<0.05)$. (C) Compared with the blank group, cell proliferation

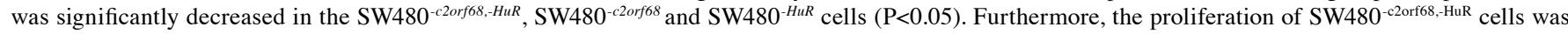
significantly lesser than that of SW480-c20r68 and SW480-HuR cells $(\mathrm{P}<0.05) .{ }^{*} \mathrm{P}<0.05$. 

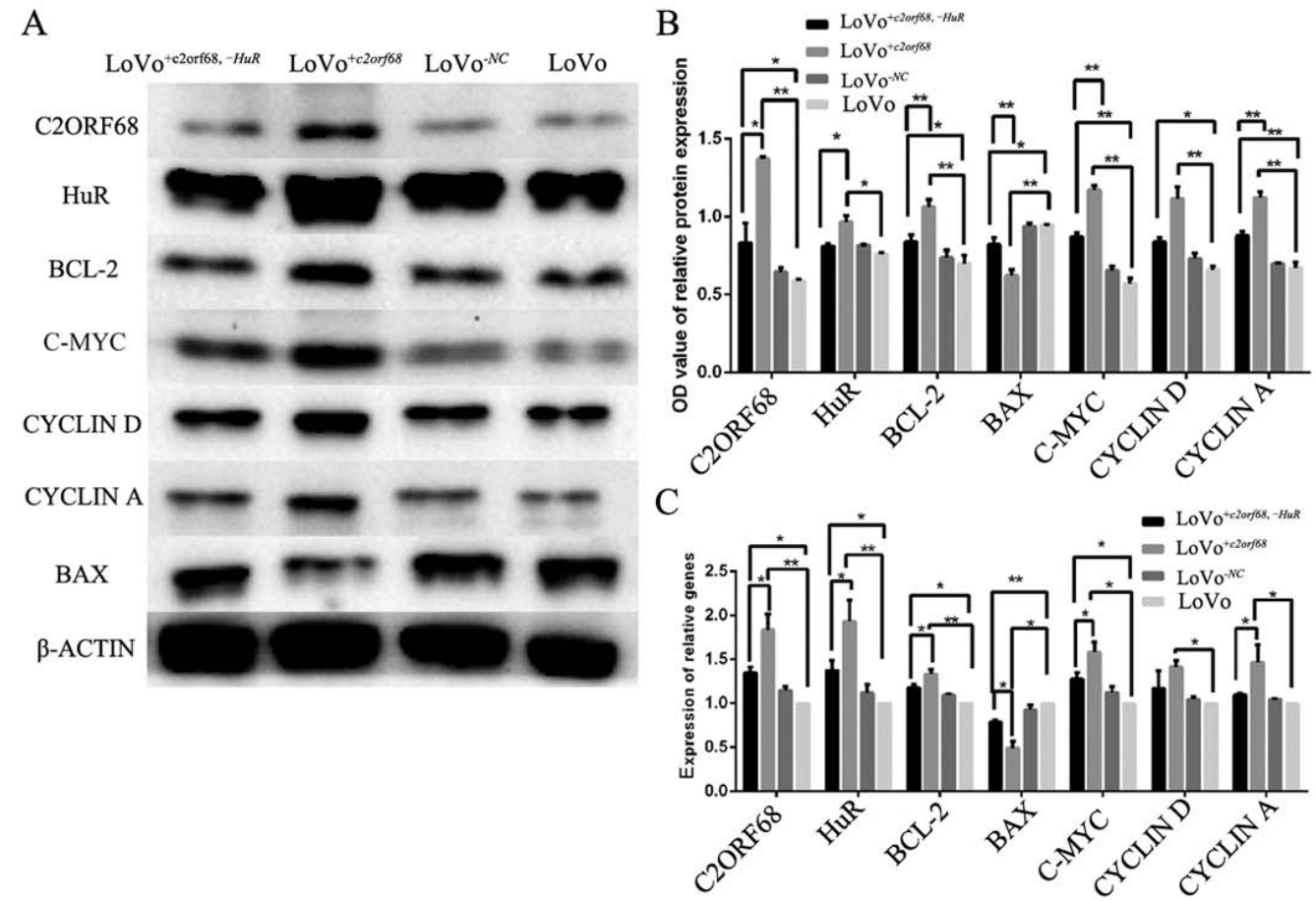

Figure 6. (A and B) The protein expression levels of C2ORF68, Bcl-2, c-Myc, cyclin D and cyclin A were overexpressed in $\mathrm{LoVo}^{+c 20 r f 68,-H u R}$ and $\mathrm{LoVO}^{+c 20 r f 68}$ cells; while HuR was overexpressed in $\mathrm{LoVo}^{+c 20 r f 68}$ cells when compared to the LoVo cells. Compared with the $\mathrm{LoVo}^{+c 20 r f 68,-H u R}$ cells, the protein expression of C2ORF68, HuR, Bcl-2, c-Myc, cyclin D and cyclin A in $\mathrm{LoVo}^{+c 2 o r f 68}$ cells was significantly increased. The protein expression level of Bax was decreased in $\mathrm{LoVo}^{+c 20 r f 68,-H u R}$ and $\mathrm{LoVo}^{+c 20 r f 68}$ cells when compared to the LoVo cells. Compared with $\mathrm{LoVo}^{+c 20 r f 68,-H u R}$ cells, the protein expression of $\mathrm{Bax}^{2} \mathrm{LoVo}^{+c 20 r f 68}$ cells was significantly decreased. (C) In $\mathrm{LoVo}^{+c 20 r f 68,-H u R}$ and $\mathrm{LoVo}^{+\mathrm{c} 20 \mathrm{r} 68}$ cells, the mRNA levels of c2orf68, HuR, Bcl-2, c-Myc were significantly overexpressed in both $\mathrm{LoVo}^{+c 20 r f 68}$ and $\mathrm{LoVo}^{+c 20 r f 68,-H u R}$ cells. Cyclin $\mathrm{D}$ and cyclin A were significantly overexpressed in $\mathrm{LoVo}^{+c 20 r f 68}$ cells, while the upregulation of cyclin $\mathrm{D}$ and cyclin A mRNA expression levels in $\mathrm{LoVo}^{+c 20 r f 68,-H u R}$ cells exhibited no significant difference. ${ }^{*} \mathrm{P}<0.05,{ }^{* *} \mathrm{P}<0.01$.

significantly higher than that of $\mathrm{LoVo}^{+c 2 o r f 68,-H u R}, \mathrm{LoVo}^{-N C}$ and LoVo cells (Fig. 4A, P<0.05).

Cell apoptosis, cell proliferation and cell migration of SW480-c2orf68,-HuR,$S W 480^{-c 2 o r f 68}$ and SW480-HuR cells. The apoptosis rate of SW480-c2orf68,-HuR cells was significantly higher than that of SW480-c2orf68, SW480-HuR, SW480 ${ }^{-N C}$ and SW480 cells (Fig. 5B, P<0.05). In addition, the apoptosis rate of SW480 ${ }^{-c 2 o r f 68}$ and SW480-HuR cells was significantly higher than that of SW480 ${ }^{-N C}$ and SW480 cells, respectively (Fig. 5B, $\mathrm{P}<0.05$ ). Compared with the control group, cell proliferation was significantly decreased in the SW480-c2orf68,-HuR, SW480 ${ }^{-c 20 r f 68}$ and SW480 $0^{-H u R}$ cells (Fig. 5C, P<0.05); cell proliferation in the SW480-c2orf68,-HuR cells was significantly less than that of the SW480-c2orf68 and SW480 ${ }^{-H u R}$ cells (Fig. 5C, P<0.05). The number of migrated cells of SW480-c2orf68,-HuR, SW480-c2orf68, SW480 ${ }^{-H u R,}$, SW480 ${ }^{-N C}$ and SW480 were $122 \pm 16,234 \pm 51$, $233 \pm 48,381 \pm 42$ and $401 \pm 24$, respectively. Compared with the control group, the number of migrated cells were significantly inhibited in the SW480-c2orf68,-HuR, SW480-c2orf68 and SW480-HuR cells (Fig. 5A, $\mathrm{P}<0.05$ ) cells. However, the number of migrated SW480-c2orf68,-HuR cells was significantly lower than that of the SW480-c2orf68 and SW480-HuR cells (Fig. 5A, P<0.05).

mRNA and protein expression of C2orf68, $\mathrm{HuR}, \mathrm{Bcl}-2$, Bax, c-Myc, cyclin D and cyclin A in LoVo ${ }^{+c 2 o r f 68,-H u R}$ and LoVo ${ }^{+c 2 o r f 68}$ cells. As shown in Fig. 6C, following transfection for $48 \mathrm{~h}$, c2orf68 gene expression was significantly overexpressed in the $\mathrm{LoVO}^{+c 20 r f 68}(\mathrm{P}<0.01)$ and $\mathrm{LoVO}^{+c 2 o r f 68,-H u R}$ cells $(\mathrm{P}<0.05)$ when compared with the control group. Similarly, $H u R, B c l-2$ and $c-M y c$ were significantly overexpressed in the $\mathrm{LoVo}^{+c 20 r f 68}(\mathrm{P}<0.01$, $\mathrm{P}<0.01$ and $\mathrm{P}<0.05$, respectively) and $\mathrm{LoVO}^{+c 2 \text { orf } 68,-H u R}$ cells (all $\mathrm{P}<0.05)$. Cyclin $D$ and $C y c l i n A$ were significantly overexpressed in the $\mathrm{LoVo}^{+c 2 o r f 68}$ cells $(\mathrm{P}<0.05)$, while the upregulation of Cyclin D and Cyclin A mRNA expression levels in LoVo ${ }^{+c 2 o r f 68,-H u R}$ cells exhibited no significance. The mRNA expression of c2orf68, HuR, Bcl-2, $c-M y c$ and Cyclin A in $\mathrm{LoVo}^{+c 2 o r f 68}$ cells was significantly increased, while cyclin $D$ in $\mathrm{LoVo}^{+c 2 o r f 68,-H u R}$ cells exhibited no statistical difference with $\mathrm{LoVo}^{+c 2 o r f 68}$ cells. In contrast, the mRNA expression level of Bax was decreased in the $\mathrm{LoVO}^{+c 2 o r f 68}(\mathrm{P}<0.05)$ and $\mathrm{LoVO}^{+c 2 o r f 68,-H u R}(\mathrm{P}<0.01)$ cells, when compared to the control. Compared with the $\mathrm{LoVo}^{+c 2 o r f 68,-H u R}$ cells, the mRNA expression of Bax in the $\mathrm{LOVO}^{+c 2 o r f 68}$ cells was significantly decreased $(\mathrm{P}<0.05)$.

As shown in Fig. 6A and B, following transfection for 48-72 h, compared to the blank group, the protein expression level of C2ORF68 was significantly increased in the $\mathrm{LoVo}^{+c 2 o r f 68,-H u R}(\mathrm{P}<0.05)$ and $\mathrm{LoVO}^{+c 2 o r f 68}(\mathrm{P}<0.01)$ cells. In addition, HuR, BCL-2, C-MYC and Cyclin A protein expression levels were overexpressed in the $\mathrm{LoVO}^{+c 2 o r f 68,-H u R}(\mathrm{NS}, \mathrm{P}<0.05$, $\mathrm{P}<0.01$ and $\mathrm{P}<0.01$, respectively) and $\mathrm{LoVO}^{+c 2 \text { rrf } 68}$ cells $(\mathrm{P}<0.05$, $\mathrm{P}<0.01, \mathrm{P}<0.01$ and $\mathrm{P}<0.01$, respectively) when compared to the blank group; compared with the $\mathrm{LoVO}^{+c 20 r f 68,-H u R}$ cells, the protein expression of C2ORF68, HuR, BCL-2, C-MYC and Cyclin A in $\mathrm{LoVO}^{+c 2 \text { orf } 68}$ cells was increased $(\mathrm{P}<0.05, \mathrm{P}<0.05, \mathrm{P}<0.01, \mathrm{P}<0.01$ and $\mathrm{P}<0.01$, respectively). In contrast, the protein expression level of BAX was decreased in the $\mathrm{LoVO}^{+c 2 o r f 68,-H u R}(\mathrm{P}<0.05)$ and $\mathrm{LoVo}^{+c 2 o r f 68}$ cells $(\mathrm{P}<0.01)$. Compared with $\mathrm{LoVO}^{+c 2 o r f 68,-H u R}$ cells, the protein expression of $\mathrm{BAX}(\mathrm{P}<0.01)$ in $\mathrm{LoVO}^{+c 2 o r f 68}$ cells was significantly decreased. 
A
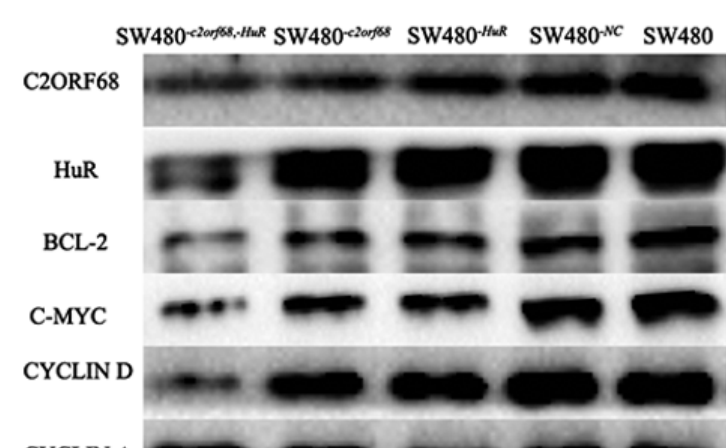

B


Figure 7. (A and B) The protein expression levels of C2ORF68, HuR, Bcl-2, c-Myc, cyclin D and cyclin D were significantly decreased. The inhibition rate of C2ORF68, HuR, Bcl-2, c-Myc, cyclin D and cyclin A was significantly higher in the SW480-c2orf68,-HuR cells than in SW480-c2orf68 and SW480-HuR cells. However, the inhibition rate of CYCLIND was not statistically significant in SW480-c2orf68,-HuR cells, compared with SW480-c2orf68 and SW480-HuR cells. Meanwhile, the protein expression level of BAX significantly increased in SW480-c2orf68,-HuR , SW480 ${ }^{-c 2 o r f 68}$ and SW480-HuR cells. (C) In the SW480-c2orf68,-HuR , SW480-c2orf68 and SW480 ${ }^{-H u R}$ cells, the mRNA expression levels of c2orf68, HuR, Bcl-2, c-Myc, cyclin D and cyclin A were significantly decreased. Furthermore, the inhibition rate of c2orf68, HuR, Bcl 2 and cyclin A in SW480-c2orf68-HuR cells was significantly higher than that in the SW480 ${ }^{-c 2 o r f 68}$ and SW480 $0^{-H u R}$ cells. The inhibition rate of cyclin D in SW480-c2orf68,-HuR cells compared with SW480-HuR cells, was statistically significant. However, compared with SW480-c2orf68 cells, the inhibition of cyclin D was not statistically significant. Furthermore, the mRNA expression level of Bax was significantly increased in the SW480 ${ }^{-c 2 o r f 68,-H u R}$, SW480-c2orf68 and SW480 ${ }^{-H u R}$ cells $(\mathrm{P}<0.01, \mathrm{P}<0.01, \mathrm{P}<0.01)$, and the expression of BAX was also increased in the SW480-c2orf68,-HuR cells when compared with the SW480-c2orf68 $(\mathrm{P}<0.05)$ and $\mathrm{SW} 480^{-H u R}(\mathrm{P}<0.05)$ cells. ${ }^{*} \mathrm{P}<0.05,{ }^{* *} \mathrm{P}<0.01$.

mRNA and protein expression of c2orf68, $\mathrm{HuR}, \mathrm{Bcl}-2, \mathrm{Bax}$, $c-M y c$, cyclin D and cyclin A in SW480-c2orf68,-HuR,$S W 480^{-c 2 o r f 68}$ and SW480-HuR cells. As shown in Fig. 7C, in SW480-c2orf68,-HuR, SW480 ${ }^{-22 o r f 68}$ and SW480 ${ }^{-H u R}$ cells, the mRNA expression level of c2orf68, HuR, Bcl-2, c-Myc, cyclin D and cyclin A significantly decreased $(\mathrm{P}<0.05)$. Furthermore, the inhibition rate of c2orf68, HuR, Bcl-2, c-Myc and cyclin A in SW480-c2orf68,-HuR cells was significantly higher than that in SW480-c2orf68 and SW480-HuR cells $(\mathrm{P}<0.05)$. The inhibition rate of cyclin $D$ in SW480-c2orf68,-HuR cells compared with SW480 ${ }^{-H u R}$ cells, was statistically significant $(\mathrm{P}<0.05)$. However, compared with SW480-c2orf68 cells, the inhibition of cyclin $D$ was not statistically significant. Meanwhile, the increase in Bax mRNA expression was significantly higher in SW480-c2orf68,-HuR cells than in SW480-c2orf68 and SW480-HuR cells $(\mathrm{P}<0.05)$. Furthermore, the mRNA expression level of Bax was increased in SW480-c2orf68,-HuR, $\mathrm{SW} 480^{-c 2 o r f 68}$ and SW480-HuR cells.

As shown in Fig. 7A and B, following transfection for 48-72 h, compared to the blank group, the protein expression level of C2ORF68 was significantly decreased in the SW480-c2orf68,-HuR $(\mathrm{P}<0.01)$, SW480-c2orf68 $(\mathrm{P}<0.01)$ and SW480-HuR cells $(\mathrm{P}<0.01)$. Similarly, the protein expression levels of HuR, BCL-2, C-MYC, Cyclin D and Cyclin A were also decreased in the SW480-c2orf68,-HuR, $\mathrm{SW} 480^{-c 20 r f 68}$ and SW480 ${ }^{-H u R}$ cells. Furthermore, the inhibition rate of C2ORF68 $(\mathrm{P}<0.01, \mathrm{P}<0.01)$, HuR $(\mathrm{P}<0.05, \mathrm{P}<0.05)$, C-MYC $(\mathrm{P}<0.05, \mathrm{P}<0.01)$ and $\mathrm{Cyclin} \mathrm{A}(\mathrm{P}<0.05, \mathrm{P}<0.05)$ was significantly higher in the SW480-c2orf68,-HuR cells than that in the SW480-c2orf68 and SW480-HuR cells. However, the inhibition rate of Cyclin D in SW480-c2orf68,-HuR cells, compared with SW480 ${ }^{-c 2 o r f 68}$ and SW480-HuR cells, was not statistically significant. Meanwhile, the protein expression level of BAX was significantly increased in the SW480-c2orf68,-HuR, SW480-c2orf68 and SW480 ${ }^{-H u R}$ cells when compared with the blank group. Compared with the SW480-c2orf68 and SW480-HuR cells, the protein expression level of BAX was significantly higher in the SW480 ${ }^{-c 2 o r f 68,-H u R}$ cells $(\mathrm{P}<0.01, \mathrm{P}<0.01)$.

\section{Discussion}

In the present study, it was shown that the expression level of C2ORF68 was significantly upregulated in rectal cancer tissues compared with its adjacent normal tissues by IHC. This indicates that $c 2$ orf68 may be involved the occurrence of rectal cancer. In addition, upregulated expression of C2ORF68 was significantly correlated with a variety of important clinicopathological parameters, including pathological grade and lymph node metastasis. It was suggested that C2ORF68 may play a role in the development and metastasis of CRC. As a result, a statistical significance was found between the expression of C2ORF68 and pathological grade. This indicates that the expression level of C2ORF68 may be associated with the malignant potential of cancer. That is, the higher the expression level of C2ORF68, the higher is the degree of malignancy of 
rectal carcinoma. These present results suggest that the $c 2$ orf 68 gene is associated with the occurrence and development of rectal cancer and may be a potential carcinogenic factor in rectal cancer. However, the detailed mechanism for $c 2$ orf68 upregulation in rectal cancer remains to be clarified.

Through bioinformatic analyses, we discovered that there are 12 proteins which interact with C2ORF68, including KLHL15, GMNN, SMG6, GNE, DDHD2, PIR, ELAVL1 (HuR), NAGK, XPO1, HSPA9, JOSD2 and GUK1(BioGrid database). At the same time, by our experiments, including IF and Co-IP, we verified that C2ORF68 co-localized with HuR in SW480 and LoVo cell lines, and C2ORF68 could interact with HuR. HuR, a member of the Hu/ELAV family, is predominantly located in the nucleus and translocates to the cytoplasm when cells are stimulated by endogenous factors or external stimuli $(21,22)$. HuR (ELAV1) is an RNA binding protein, which has been shown to regulate the expression of multiple genes by different post-transcriptional mechanisms, such as mRNA decay and protein translation (23). HuR modulates posttranscriptional processing of target premRNAs or mRNA stabilization and translation through interaction with AU-rich elements (ARE) within 3'-untranslated regions (UTRs) of the target mRNAs to transformation (24). Furthermore, it has been shown that HuR stabilizes mRNAs that encode p53 and WEE1 (25), activates ATF2 (26), Jun D (27) and XIAP (28) and enhances the translation of mRNAs that encode $c-M y c$ (29), ICH-I (30) and IL-1 $\beta$ (31). Many of these transcripts are reported to participate in certain key cellular processes including cell proliferation, cell apoptosis, angiogenesis, immune response and metastasis. HuR is also increased in malignant cells when compared with corresponding normal cells, and it has been found to be associated with adverse clinicopathological factors in several different cancer types, such as gastric, gallbladder breast, urothelial and non-small cell lung cancer (32).

Our study revealed that cell apoptosis increased, cell proliferation and cell migration decreased when 22 orf 68 was inhibited in SW480 cells. These results are consistent with our previous study (16). In addition, we also demonstrated that cell apoptosis increased while cell proliferation and cell migration decreased in SW480 ${ }^{-H u R}$ and SW480-c2orf68,-HuR cells. This indicates that both $c 2$ orf 68 and $H u R$ can regulate cell apoptosis and proliferation in CRC cells. The cell apoptosis rate, cell proliferation and cell migration in SW480-c20rf68,-HuR cells which has more significant results than that in SW480-HuR cells revealed that $c 2$ orf 68 and $H u R$ may have a synergistic effect in regulating cell apoptosis, cell proliferation and cell migration. This study differed from our previous study (16), which focused on the PI3K/Akt/mTOR signaling pathway and its downstream molecules, such as $A k t, P I 3 K, B c l-2, c-M y c$, cyclin D1 and bax when c2orf68 was inhibited. A recent study showed that the HuR expression level is closely related to AKT phosphorylation and PI3K/AKT/NF- $\mathrm{kB}$ signaling can notably elevate $H u R$ gene transcription (18). This study focused on the relationship between C2ORF68 and HuR and the downstream molecules of $H u R$, such as Bcl-2, Bax, c-Myc, cyclin D and cyclin A in SW480-c2orf68,-HuR, SW480 -c2orf68 and SW480-HuR cells. According to our results, $B c l-2, c-M y c$, cyclin $D$ and Cyclin A decreased, and Bax increased in the SW480-220rf68,-HuR, SW480-c2orf68 and SW480-HuR cells. In addition, Bcl-2, $c-M y c$, cyclin $D$ and cyclin $A$ was significantly decreased and Bax was significantly increased in SW480 ${ }^{-c 20 r f 68,-H u R}$ cells. This shows that $c 20 r f 68$ and $H u R$ may co-regulate $B c l-2, c-M y c$, cyclin D, cyclin $A$ and Bax, resulting in the cell apoptosis and cell proliferation CRC cells.

In the present study, the mRNA and protein expression of $H u R$ was downregulated when $c 20 r f 68$ was inhibited in SW480 cells, and the mRNA and protein expression of $H u R$ was upregulated when c2orf68 was overexpressed in LoVo cells. Furthermore, when $H u R$ was inhibited, the mRNA and protein expression levels of $c 2$ orf 68 were also decreased. That is, $H u R$ and $c 2$ orf 68 had a synergistic effect.

The present study revealed that cell apoptosis decreased while cell proliferation and cell migration were increased in $\mathrm{LoVO}^{+c 20 r f 68}$ cells. These results are consistent with our previous study (17), and it was confirmed that $c 20 r f 68$ can regulate cell apoptosis and proliferation. In addition, it was also revealed that cell apoptosis was decreased when cell proliferation and cell migration were increased in $\mathrm{LoVO}^{+c 2 o r f 68,-H u R}$ cells. However, cell apoptosis was significantly lower and cell proliferation and cell migration were significantly higher in $\mathrm{LoVo}^{+c 20 r f 68}$ cells, compared with $\mathrm{LoVO}^{+c 20 r f 68,-H u R}$ cells. All these results suggest again that $c 2$ orf 68 and $H u R$ may have a synergistic effect in promoting cell proliferation and migration, and in inhibiting cell apoptosis in the role of CRC. Unlike our previous study, which focused on the Wnt signaling pathway and its molecules

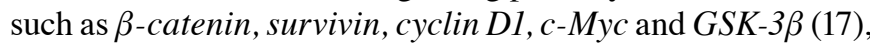
the present study focused on the relationship between C2ORF68 and HuR and the downstream molecules of $H u R$ such as Bcl-2, Bax, c-Myc, cyclin D and cyclin A. In LoVo ${ }^{+c 2 o r f 68}$ and $\mathrm{LoVo}^{+c 2 o r f 68,-H u R}$ cells, Bcl-2, c-Myc, cyclin D and cyclin A increased, while $B a x$ decreased. In addition, $B c l-2, c-M y c$, cyclin $D$ and cyclin $A$ were significantly upregulated and Bax was significantly decreased in $\mathrm{LoVo}^{+c 20 r f 68}$ cells, compared with $\mathrm{LoVo}^{+c 20 r f 68,-H u R}$ cells. Previously in this manuscript, we described that $B c l-2, c-M y c$, cyclin $D$ and $c y c l i n A$ were decreased, while Bax was increased in the SW480-20rf68,-HuR, SW480 ${ }^{-c 2 o r f 68}$ and SW480 ${ }^{-H u R}$ cells. In addition, Bcl-2, c-Myc, cyclin $D$ and cyclin $A$ were significantly decreased and Bax was significantly increased in the SW480 -c2orf68,-HuR cells, compared with the SW480-c2orf68 and SW480-HuR cells. It is known that all these genes are involved in key cellular processes such as cell proliferation and cell cycle. The expression of cyclin D1 is increased in many tumors and it promotes cell proliferation by regulating cell cycle progression through the $\mathrm{G} 1 / \mathrm{S}$ restriction point (33). The transcription factor c-Myc, which is a leucine zipper protein regulating the expression of $10-15 \%$ of human genes, plays an important role in cell proliferation, differentiation, growth and survival. Its overexpression is associated with cancer occurrence and development (34). BCL-2, an integral outer mitochondrial membrane protein, serving as an anti-apoptosis protein, belongs to the Bcl-2 family, and was firstly discovered in B cell malignancies and regulates the intrinsic mitochondrial apoptosis pathway (35). Activated Bax then oligomerizes at the mitochondria to induce outer mitochondrial membrane (OMM) permeabilization and releases into the cytosol apoptotic factors which promote caspase activation and subsequent apoptosis execution (36). Cyclins are fundamental regulators of the cell cycle, playing an important role in tumorigenesis, Cyclin A is required for cells to progress through the $\mathrm{S}$ phase (37). As a result, it is believed that $c 2$ orf 68 
and $H u R$ may have a synergistic effect and may co-regulate cell proliferation and apoptosis by regulating the downstream molecules of $\mathrm{HuR}$, such as upregulating $\mathrm{Bcl}-2, \mathrm{c}$-Myc, cyclin $\mathrm{D}$ and $c y c l i n A$ gene expression and downregulating Bax gene expression, resulting in the development of cancer.

In conclusion, the $c 2$ orf6 8 gene may be a potential oncogene and may play a potential carcinogenic effect in the pathogenesis of colorectal cancer. Furthermore, it may be associated with lymph node metastasis of colorectal cancer. The carcinogenesis of $c 2$ orf 68 may be related to the promotion of cell proliferation and inhibition of cell apoptosis. $C 20 r f 68$ may have a synergistic effect with $H u R$, and the possible mechanism of $c 20 r f 68$ and $H u R$ involves the co-promotion of cell proliferation and migration, and the co-inhibition of cell apoptosis. However, the exact mechanism remains mysterious. C2orf68 and HuR may co-regulate cell proliferation and apoptosis by upregulating $B c l-2, c-M y c$, cyclin $D$ and $c y c l i n A$ gene expression and downregulating Bax gene expression, resulting in the development of colorectal cancer. Our previous study indicated that C2ORF68 can regulate cancer cell proliferation and apoptosis through PI3K/AKT/mTOR signaling (16). At the same time, a recent study (18) showed that the HuR expression level is closely related to AKT phosphorylation and cytoplasmic abundance of HuR in human cancer may be associate with oncogenic activation of AKT signaling. According to the above conclusions, we may hypothesize that C2ORF68, HuR and AKT signaling could make up a mutually reinforcing loop, regulating cancer cell proliferation and apoptosis. However, the specific mechanism warrants further research.

\section{Acknowledgements}

I need to express my sincere gratitude to all authors for the assistance with this article, especially to Professor Yao Chen, whose constant encouragement directed me through all stages of the writing of this manuscript. Without her help, I could not have gotten to this point. Furthermore, I also extend my heartfelt gratitude to the other authors, and thanks for their efforts.

\section{Funding}

The present study was supported by Chengdu Department of Science and Technology (2018-YF05-00-038-SN), Sichuan Province, China.

\section{Availability of data and materials}

The datasets used during the present study are available from the corresponding author upon reasonable request.

\section{Authors' contributions}

LS, KS, TJ and YC conceived and designed the study. ZL and $\mathrm{KH}$ performed the experiments. ZL and $\mathrm{KH}$ wrote the paper. LS, KS, TJ and YC reviewed and edited the manuscript. All authors read and approved the manuscript and agree to be accountable for all aspects of the research in ensuring that the accuracy or integrity of any part of the work are appropriately investigated and resolved.

\section{Ethics approval and consent to participate}

The Medical Research Ethics Committee of Sichuan University approved the sample acquisition (Chengdu, China), and a written informed consent was also obtained from all patients.

\section{Patient consent for publication}

Not applicable.

\section{Competing interests}

The authors state that they have no competing interests.

\section{References}

1. Siegel RL, Miller KD and Jemal A: Cancer statistics, 2017. CA Cancer J Clin 67: 7-30, 2017.

2. Lin J, Chuang CC and Zuo L: Potential roles of microRNAs and ROS in colorectal cancer: Diagnostic biomarkers and therapeutic targets. Oncotarget 8: 17328-17346, 2017.

3. Fang Y, Liang X, Jiang W, Li J, Xu J and Cai X: Cyclin B1 suppresses colorectal cancer invasion and metastasis by regulating e-cadherin. PLoS One 10: e0126875, 2015.

4. Schreuders EH, Ruco A, Rabeneck L, Schoen RE, Sung JJ, Young GP and Kuipers EJ: Colorectal cancer screening: A global overview of existing programmes. Gut 64: 1637-1649, 2015.

5. Jeyakumar A, Dissabandara L and Gopalan V: A critical overview on the biological and molecular features of red and processed meat in colorectal carcinogenesis. J Gastroenterol 52: 407-418, 2017.

6. Sakamoto N, Feng Y, Stolfi C, Kurosu Y, Green M, Lin J, Green ME, Sentani K, Yasui W, McMahon M, et al: BRAF ${ }^{\mathrm{V} 600 \mathrm{E}}$ cooperates with CDX2 inactivation to promote serrated colorectal tumorigenesis. Elife 6: e20331, 2017.

7. Raskov H, Pommergaard HC, Burcharth $\mathrm{J}$ and Rosenberg J: Colorectal carcinogenesis-update and perspectives. World J Gastroenterol 20: 18151-18164, 2014.

8. Lech G, Słotwiński R, Słodkowski M and Krasnodębski IW: Colorectal cancer tumour markers and biomarkers: Recent therapeutic advances. World J Gastroenterol 22: 1745-1755, 2016.

9. Huang L, Wang X, Wen C, Yang X, Song M, Chen J, Wang C, Zhang B, Wang L, Iwamoto A, et al: Hsa-miR-19a is associated with lymph metastasis and mediates the TNF- $\alpha$ induced epithelial-to-mesenchymal transition in colorectal cancer. Sci Rep 5: 13350, 2015.

10. Kurebayashi H, Goi T, Shimada M, Tagai N, Naruse T, Nakazawa T, Kimura Y, Hirono Y and Yamaguchi A: Prokineticin 2 (PROK2) is an important factor for angiogenesis in colorectal cancer. Oncotarget 6: 26242-26251, 2015.

11. Ingebrigtsen VA, Boye K, Nesland JM, Nesbakken A, Flatmark K and Fodstad Ø: B7-H3 expression in colorectal cancer: Associations with clinicopathological parameters and patient outcome. BMC Cancer 14: 602, 2014.

12. Yamaguchi K, Yamaguchi R, Takahashi N, Ikenoue T, Fujii T, Shinozaki M, Tsurita G, Hata K, Niida A, Imoto S, et al: Overexpression of cohesion establishment factor DSCC1 through E2F in colorectal cancer. PLoS One 9: e85750, 2014.

13. Thomas J, Ohtsuka M, Pichler M and Ling H: MicroRNAs: Clinical relevance in colorectal cancer. Int J Mol Sci 16: 28063-28076, 2015.

14. Lam SY, Yu J, Wong SH, Peppelenbosch MP and Fuhler GM: The gastrointestinal microbiota and its role in oncogenesis. Best Pract Res Clin Gastroenterol 31: 607-618, 2017.

15. Wang $\mathrm{K}$ and Chen Y: Analysis of a novel protein in human colorectal adenocarcinoma. Mol Med Rep 8: 529-534, 2013.

16. Wen X, Zhu J, Dong L and Chen Y: The role of c2orf68 and PI3K/Akt/mTOR pathway in human colorectal cancer. Med Oncol 31: 92, 2014.

17. Chen Y, Jiang T, Shi L and He K: hercn81 promotes cell proliferation through Wnt signaling pathway in colorectal cancer. Med Oncol 33: 3, 2016. 
18. Kang MJ, Ryu BK, Lee MG, Han J, Lee JH, Ha TK, Byun DS, Chae KS, Lee BH, Chun HS, et al: NF-kappaB activates transcription of the RNA-binding factor $\mathrm{HuR}$, via PI3K-AKT signaling, to promote gastric tumorigenesis. Gastroenterology 135: 2030-2042.e1-e3, 2008.

19. He K, Shi L, Jiang T, Li Q, Chen Y and Meng C: Association between SET expression and glioblastoma cell apoptosis and proliferation. Oncol Lett 12: 2435-2444, 2016.

20. Livak KJ and Schmittgen TD: Analysis of relative gene expression data using real-time quantitative PCR and the $2^{-\Delta \Delta C T}$ method. Methods 25: 402-408, 2001.

21. Woodhoo A, Iruarrizaga-Lejarreta $M$, Beraza $N$, García-Rodríguez JL, Embade N, Fernández-Ramos D, Martínez-López N, Gutiérrez-De Juan V, Arteta B, Caballeria J, et al: Human antigen $\mathrm{R}$ contributes to hepatic stellate cell activation and liver fibrosis. Hepatology 56: 1870-1882, 2012.

22. Zhang LF, Lou JT, Lu MH, Gao C, Zhao S, Li B, Liang S, Li Y, Li D and Liu MF: Suppression of miR-199a maturation by HuR is crucial for hypoxia-induced glycolytic switch in hepatocellular carcinoma. EMBO J 34: 2671-2685, 2015.

23. Jakstaite A, Maziukiene A, Silkuniene G, Kmieliute K, Gulbinas A and Dambrauskas Z: HuR mediated post-transcriptional regulation as a new potential adjuvant therapeutic target in chemotherapy for pancreatic cancer. World J Gastroenterol 21: 13004-13019, 2015.

24. Zhu H, Berkova Z, Mathur R, Sehgal L, Khashab T, Tao RH, Ao X, Feng L, Sabichi AL, Blechacz B, et al: HuR suppresses fas expression and correlates with patient outcome in liver cancer. Mol Cancer Res 13: 809-819, 2015.

25. Lal S, Burkhart RA, Beeharry N, Bhattacharjee V, Londin ER, Cozzitorto JA, Romeo C, Jimbo M, Norris ZA, Yeo CJ, et al: HuR posttranscriptionally regulates WEE1: Implications for the DNA damage response in pancreatic cancer cells. Cancer Res 74: $1128-1140,2014$

26. Xiao L, Rao JN, Zou T, Liu L, Marasa BS, Chen J, Turner DJ, Zhou H, Gorospe $\mathrm{M}$ and Wang JY: Polyamines regulate the stability of activating transcription factor- 2 mRNA through RNA-binding Protein HuR in intestinal epithelial cells. Mol Biol Cell 18: 4579-4590, 2007.

27. Zou T, Rao JN, Liu L, Xiao L, Yu TX, Jiang P, Gorospe M and Wang JY: Polyamines regulate the stability of JunD mRNA by modulating the competitive binding of its $3^{\prime}$ untranslated region to HuR and AUF1. Mol Cell Biol 30: 5021-5033, 2010.
28. Zhang X, Zou T, Rao JN, Liu L, Xiao L, Wang PY, Cui YH, Gorospe M and Wang JY: Stabilization of XIAP mRNA through the RNA binding protein HuR regulated by cellular polyamines. Nucleic Acids Res 42: 4143, 2014.

29. Liu L, Rao JN, Zou T, Xiao L, Wang PY, Turner DJ, Gorospe M and Wang JY: Polyamines regulate c-Myc translation through Chk2-dependent HuR phosphorylation. Mol Biol Cell 20: 4885-4898, 2009.

30. Winkler C, Doller A, Imre G, Badawi A, Schmid T, Schulz S, Steinmeyer N, Pfeilschifter J, Rajalingam K and Eberhardt W: Attenuation of the ELAV1-like protein HuR sensitizes adenocarcinoma cells to the intrinsic apoptotic pathway by increasing the translation of caspase-2L. Cell Death Dis 5: e1321, 2014.

31. Aguado A, Rodríguez C, Martínez-Revelles S, Avendaño MS, Zhenyukh O, Orriols M, Martínez-González J, Alonso MJ, Briones AM, Dixon DA and Salaices M: HuR mediates the synergistic effects of angiotensin II and IL-1 $\beta$ on vascular COX-2 expression and cell migration. Br J Pharmacol 172: 3028-3042, 2015.

32. Elebro J, Ben Dror L, Heby M, Nodin B, Jirström K and Eberhard J: Prognostic effect of hENT1, dCK and HuR expression by morphological type in periampullary adenocarcinoma, including pancreatic cancer. Acta Oncol 55: 286-296, 2015.

33. Li X, Zhang Q, Fan K, Li B, Li H, Qi H, Guo J, Cao Y and Sun H: Overexpression of TRPV3 correlates with tumor progression in non-small cell lung cancer. Int J Mol Sci 17: 437, 2016.

34. Sharma T, Bansal R, Haokip DT, Goel I and Muthuswami R: SMARCAL1 negatively regulates C-Myc transcription by altering the conformation of the promoter region. Sci Rep 9: $17910,2015$.

35. Choi JE, Kang SH, Lee SJ and Bae YK: Prognostic significance of Bcl-2 expression in non-basal triple-negative breast cancer patients treated with anthracycline-based chemotherapy. Tumor Biol 35: 12255-12263, 2014

36. Ouyang YB and Giffard RG: microRNAs affect BCL-2 family proteins in the setting of cerebral ischemia. Neurochem Int 77: 2-8, 2014.

37. Kokontis JM, Lin HP, Jiang SS, Lin CY, Fukuchi J, Hiipakka RA, Chung CJ, Chan TM, Liao S, Chang CH, et al: Androgen suppresses the proliferation of androgen receptor-positive castration-resistant prostate cancer cells via inhibition of Cdk2, CyclinA, and Skp2. PLoS One 9: e109170, 2014. 